\title{
Formación de palabras, gramática y diccionario
}

\author{
Jesús Pena \\ Universidade de Santiago
}

Bajo este título quiero exponer algunos aspectos concretos que permitan establecer una comparación y contraste entre formación de palabras y gramática, de un lado, y entre formación de palabras y diccionario o lexicografía, de otro, con el fin de mostrar cómo difieren las tres disciplinas en cuanto a objeto y a objetivos, pero también cómo son disciplinas que se complementan entre sí.

Una observación previa que servirá de entrada en la exposición. Cada día que pasa, el lingüista es más consciente de que existe un hiato o divorcio entre gramática y diccionario o, en términos generales, entre el estudio de la gramática y el estudio del léxico. Desde hace ya algún tiempo y desde corrientes teóricas diversas, se viene insistiendo en la necesidad de estudiar las relaciones entre el léxico y la gramática. Al gramático y al estudioso del léxico se les exige que den información gramatical más precisa 0 refinada acerca de los rasgos categoriales de la palabra y de sus posibilidades combinatorias. Y, de hecho, cada vez se analizan con más finura las propiedades gramaticales del léxico pues resultan pertinentes tanto para las reglas sintácticas (RS), como para las reglas de formación de palabras (RFP). Así, aparte de indicar la categoría léxica a la que se adscribe el lexema, se delimitan una serie de rasgos, tanto los que atañen a las propiedades de la clase léxica en sí (rasgos inherentes), como a sus posibilidades combinatorias.

Pero hasta hace relativamente poco tiempo, en ese puente que se intenta tender entre gramática y diccionario, la gran ausente ha sido la disciplina que se ocupa de la formación de palabras. Habrá que esperar a mediados de los años setenta para que la gramática generativa desarrolle el componente léxico de una lengua.

FORMACIÓN DE PALABRAS Y GRAMÁTICA: COMPETENCIA LÉXICA Y COMPETENCIA SINTÁCTICA

La creación de la morfología, dentro de la GGT, conlleva el desarrollo del componente léxico de la gramática como un componente autónomo con objetivos, reglas y principios específicos que rigen tales reglas: los procesos de formación de palabras se dan en el componente léxico y las reglas de formación de palabras (RFP) son específicas de dicho componente. 
La razón para deslindar un componente morfológico dentro de la gramática de una lengua está en que la competencia del hablante le permite no sólo comprender y emplear palabras de su lengua, sino también tener conocimientos acerca de su estructura y de su significado en consonancia con su estructura. Un hablante español sabe que rebuscamiento o remodelación son palabras derivadas y reconoce su estructura. Además, es capaz de crear nuevas palabras y de saber cuáles están bien formadas y cuáles no, cf.

(1)

bayeta $\rightarrow$ bayetar "limpiar o fregar el suelo con bayeta" (cf. escobilla $\rightarrow$ escobillar). $\rightarrow$ bayetear "limpiar repetidamente o fregotear el suelo con bayeta" / "dar golpes con la bayeta" (cf. martillo $\rightarrow$ martillear).

$\longrightarrow$ *bayetecer, *bayetificar, *bayetizar...

moreno,-a $\rightarrow$ morenar "poner(se) moreno (a) alguien" (cf. azul $\rightarrow$ azular).

$\rightarrow$ amorenar (cf. feo,-a $\rightarrow$ afear).

$\rightarrow$ enmorenar (cf. rojo,-a $\rightarrow$ enrojar).

$\longrightarrow$ morenear "tener color moreno" / "tirar a moreno" (cf. rojo,-a $\longrightarrow$ rojear). $\longrightarrow$ *(a-,en-)morenecer, *morenizar, *morenificar...

frágil $\rightarrow$ fragilizar (cf. ágil $\longrightarrow$ agilizar).

$\longrightarrow$ *fragilar, *fragilear, *fragilificar...

paciencia $\rightarrow$ pacienciar (cf. diferencia $\longrightarrow$ diferenciar).

$\longrightarrow$ *paciencear, *paciencificar, *paciencizar...

comarcal $\rightarrow$ comarcalizar (cf. legal $\rightarrow$ legalizar).

$\longrightarrow$ *comarcalar, *comarcalear, *comarcalificar...

confesable $\longrightarrow$ inconfesable/confesar $\longrightarrow$ *inconfesar/confesión $\longrightarrow$ *inconfesión.

leer $\rightarrow$ releer/ verdad $\longrightarrow$ *reverdad.

animar $\longrightarrow$ animación/feo,-a $\longrightarrow *$ feación.

beatificar $\rightarrow$ beatificación/*beatificamiento.

cristianizar $\longrightarrow$ cristianización/*cristianizamiento.

florecer $\longrightarrow$ florecimiento/*florecición.

matar $\longrightarrow$ matanza/absorber $\longrightarrow$ *absorbenza/concurrir $\longrightarrow$ *concurrenza.

La competencia lingüística del hablante incluye una competencia léxica en el ámbito de las palabras derivadas (no en el de las palabras simples, que tiene que aprender o memorizar). Esta competencia derivativa puede definirse como un conjunto de reglas, es decir, de relaciones que unen de manera regular las propiedades formales y semánticas de una palabra derivada con las de la palabra base de derivación. La gramática, como modelo de la competencia o conocimiento del hablante, debe disponer de algún componente que dé cuenta de hechos como los ejemplificados en (1). Esto quiere decir que, así como la sintaxis debe definir la clase de oraciones posibles en una lengua, de igual modo las RFP deben definir la clase de palabras posibles en una lengua. La finalidad de las reglas del componente léxico (RFP) consiste, pues, en definir los procedimientos mediante los cuales se forman nuevas palabras y se analizan las ya existentes. No se trata de asimilar completemante la competencia léxica a la competencia sintáctica, sino de subrayar las semejanas entre las dos, al menos en lo que concierne 
a las posibilidades de crear nuevas unidades (oraciones y palabras respectivamente) y de asignarles un significado ${ }^{1}$.

FORMACIÓN DE PALABRAS Y DICCIONARIO

La distinción entre competencia y realización, o entre sistema y norma en sentido coseriano, es pertinente en cualquier componente de la lengua. Tal distinción, aplicada al léxico, viene a corresponder grosso modo con la formación de palabras y el diccionario, respectivamente. El dominio de investigación de la formación de palabras es la competencia derivativa, es decir, la capacidad (o posibilidad) de producir y comprender un número infinito de palabras a partir de un número finito de RFP. El dominio del diccionario es el saber léxico convencional, es decir, la puesta en práctica de esa competencia derivativa. Dicho en términos de Coseriu², el diccionario contiene la realización normal del sistema de formación de palabras, es decir, lo que en el hablar concreto es repetición de modelos anteriores. Si para las RFP la distinción pertinente es "palabra posible/palabra imposible", para el diccionario es "palabra posible/palabra real, documentada o registrada". Un ejemplo:

(2)

documento
experimento
ornamento
parlamento
reglamento
rudimento

(a)

documental experimental ornamental parlamentario reglamentario rudimentario (b) documentario experimentario ornamentario parlamental reglamental rudimental

Sobre los sustantivos en -mento es posible formar tanto los adjetivos de la columna (a), como los de la columna (b); pero se realizan normalmente solo los de la columna (a), que son los que figuran en el diccionario. Lo que la competencia permite al hablante es la posibilidad de hacer una elección; lo que la norma exige y el diccionario, consiguientemente, registra es tal elección particular de entre las formaciones posibles. Se trata en este caso de una elección convencional entre sufijos funcional y semánticamente concurrentes.

El dominio de investigación de la formación de palabras, como sistema de posibilidades, tiene un carácter infinito respecto al número de palabras posibles. En primer lugar, tiene como posibles bases de derivación todas las raíces de significado léxico de una lengua (incluidos los nombres propios). El español, como las demás 
lenguas de nuestro entorno, no utiliza las raíces desnudas sino que las codifica categorizándolas en las llamadas clases de palabras. Ciñéndonos a las tres clases léxicas de palabras (sustantivo $(\mathrm{S})$, adjetivo $(\mathrm{A})$ y verbo $(\mathrm{V})$ ), toda raíz es susceptible de categorizarse bajo tales clases. Así, si una raíz es originariamente verbal, se categoriza primariamente como verbo y secundariamente como sustantivo y adjetivo (crear $\longrightarrow$ creación y creador, creable y creativo); si originariamente es nominal, se categoriza primariamente como sustantivo y secundariamente como adjetivo y verbo (línea $\longrightarrow$ lineal y alinear); si originariamente es adjetiva, se categoriza primariamente como adjetivo y secundariamente como verbo y sustantivo (blanco $\rightarrow$ blanquear y blancura). Hay que subrayar, a este respecto, que las RFP constituyen la gramática o, mejor dicho, la primera gramática del léxico de una lengua, es decir, imponen el primer "cómo" o "modo de significar" al significado léxico de la raíz ${ }^{3}$. Sobre esta primera categorización, las reglas flexivas (RF) operan superponiendo un segundo filtro o categorización más refinada.

Las RFP no agotan su papel en esta primera fase o ciclo de derivación. Cualquiera de las tres categorías léxicas categorizadas en la primera fase de derivación puede ser recategorizada o subcategorizada en sucesivas fases. Por poner solo algún ejemplo, en crear $\rightarrow$ creación, creador, creable, creativo, crear aparece subcategorizada como recrear, creación como creacionismo; creativo y creable pueden recategorizarse como sustantivos en creatividad y creabilidad, etc. En blanco $\rightarrow$ blanquear y blancura, blanco se recategoriza también como verbo en emblanquecer y aparece subcategorizada como blanquecino, blancuzco, etc.

¿Hay límites en las series de formación de palabras? Sí. Algún ejemplo. En la subserie crear, creativo, creatividad, la última palabra (creatividad) cierra el ciclo. En la subserie crear, creación queda excluida (="bloqueada") la derivación verbal sobre creación (que, de formarse, sería creacionar) por existir ya crear como base de derivación, guardando verbo y sustantivo una relación formal y semántica en todas sus acepciones $^{4}$. El prefijo negativo in- se añade a bases de la clase adjetivo (cf. decente $\rightarrow$ indecente, deseable $\longrightarrow$ indeseable), pero la prefijación con in- queda bloqueada en be$\mathrm{Ilo} \rightarrow$ *imbello por la existencia del adjetivo antónimo feo.

Propiedades como las indicadas (el término o cierre en una subserie de derivación, o la condición de bloqueo) invitan a pensar que el caudal léxico posible de una lengua, aunque numeroso, es limitado. Pero, como contrapartida, está el hecho de que varias

3 Vid. E. CoSeRIU (1978), pp. 136 y ss.

4 Cuando no se da esa condición, el bloqueo deja de operar. En la serie instruir, instrumento, instrumentar, la creación de instrumentar viene motivada por la ausencia de relación semántica entre instruir e instrumento. En meter, misión, misionar, la existencia de misionar viene motivada por la ausencia de relación formal y semántica entre meter y misión. También es posible la derivación de un verbo sobre el sustantivo postverbal cuando tal sustantivo solo filtra alguna o algunas de las acepciones del verbo base, que son las que suelen pasar al verbo derivado, cf. ornar $\rightarrow$ ornamento $\rightarrow$ ornamentar, influir $\longrightarrow$ influencia $\longrightarrow$ influenciar, promover $\rightarrow$ promoción $\longrightarrow$ promocionar, etc. Vid. J. PENA (1993), pp. 224-227. 
de las RFP pueden reaplicarse de manera cíclica sobre la misma base. Veamos el siguiente ejemplo (tomado de Corbin ${ }^{5}$, con las adaptaciones pertinentes al español):

$\begin{array}{lccc}(3) & & & \\ 1=i n- & 1 & \text { precede a } & 3 \\ 2=\text { des- } & 2 & “ & 4 \\ 3=-i z-a- & 3 & “ & 2,4 \\ 4=- \text { ble } & 4 & “ & 1,3\end{array}$

Conjuntos de ciclos de derivación:

1) Comienza por la prefijación de in-:

(a)

1-3-4-1

mortal inmortal inmortalizar inmortalizable inimortalizable

$\cdots$

2) Comienza por la sufijación de -iz-a-:

(d)

3-4-1-3

mortal

mortalizar

mortalizable

inmortalizable

inmortalizabilizar (b)

1-3-4-3

mortal

inmortal

inmortalizar

inmortalizable

inmortalizabilizar

(e)

3-4-3

mortal

mortalizar

mortalizable

mortalizabilizar (c)

1-3-2-4-1

mortal

inmortal

inmortalizar

desinmortalizar

desinmortalizable

indesinmortalizable

...

(f)

3-2-4-3

mortal

mortalizar

desmortalizar

desmortalizable

desmortalizabilizar

Figuran aquí cuatro afijos que pueden reaplicarse en la misma serie derivativa en el orden indicado, dando lugar a ciclos abiertos de formaciones posibles. Los ciclos se agrupan en conjuntos según la regla de afijación que sirva como punto de partida. Ahí sólo figuran dos de los cuatro conjuntos de ciclos posibles: el que comienza por la prefijación de in- y el que comienza por la sufijación de -iz-a-. Lo que interesa destacar es la recursividad ad infinitum en cualquiera de los dos conjuntos de ciclos de derivación.

Frente al caudal no finito de palabras posibles en una lengua según las RFP, está el diccionario que, como código de la norma (o, mejor dicho, como código de las palabras reales en sentido de documentadas), es necesariamente finito, por muy numeroso que sea y por muchas que sean las dificultades para registrar la totalidad. Sirva como contraste uno de los ejemplos de palabras posibles mostradas en (1): sobre la base moreno,-a, categorizada como adjetivo, se puede crear el verbo y el sustantivo correspondientes. El diccionario constata la existencia del sustantivo morenura (con su doblete morenez), pero no la del verbo o verbos posibles. Entramos en una de las pro-

5 Vid. D. CORBIN (1980), pp. 85-90. 
piedades particulares del componente léxico de una lengua (frente al componente gramatical): las lagunas del léxico, en este caso, las lagunas en las series de derivación.

En efecto, las RFP aparecen normalmente caracterizadas por la propiedad de ser opcionales (frente a, por ejemplo, las reglas flexivas y las reglas sintácticas). Ahora bien, por lo que afecta a las lagunas en las series de derivación, conviene distinguir, tal como hace Corbin ${ }^{6}$, dos tipos: las lagunas sistemáticas y las lagunas accidentales. Las primeras son lagunas predecibles pues corresponden a RFP improductivas. Por ejemplo, no se puede derivar sobre moreno,-a un verbo como *(a/en-)morenecer porque la sufijación o circunfijación con -ec-e- es hoy improductiva. El segundo tipo de lagunas, las accidentales, hace referencia a palabras no documentadas pero posibles, pues se corresponden con o son el resultado de RFP productivas. Son estas, por tanto, lagunas rellenables sistemáticamente. ¿Qué hace el lexicógrafo con este tipo de lagunas? Veamos los ejemplos de

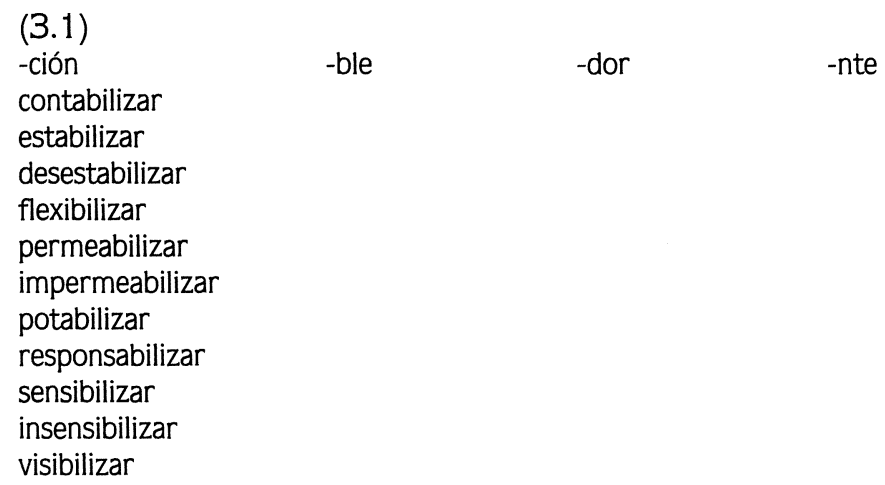

Según el diccionario inverso de l.Bosque y M. Pérez Fernández (basado en el DRAE (1984) y en el DCELC (1980)), solo figuran estos once verbos derivados en -iz-a- sobre adjetivos postverbales en -ble. Es llamativo este hecho, primero, por la existencia de un gran número de adjetivos postverbales en -ble, sufijo muy productivo y sometido a muy pocas restricciones, y, segundo, porque, en cuanto al sistema, el único sufijo verbalizador de adjetivos en -ble es -iz-a-. He puesto al lado de esos once verbos cuatro sufijos productivos (-ción, -ble, -dor y -nte) que pueden tomar como base de derivación tales verbos en -bil-iz-a- $r$ y he dejado en blanco los resultados reales para que el lector adivine, de acuerdo con su conocimiento real de la norma del español, cuáles figuran en los diccionarios y cuáles no y, de paso, contraste con sorpresa los resultados.

Por otro lado, los nombres en -ción aparecen siempre definidos como "acción y efecto de V" (cf. estabilización "acción y efecto de estabilizar") y el nombre en -dor correspondiente mediante la paráfrasis "que + V" (cf. estabilizador "que estabiliza"). Se trata, pues, de significados predecibles (de acuerdo con las RFP correspondien-

6 Vid. D. CORBIN (1976b), p. 95). 
tes), en definitiva, de formaciones totalmente regulares tanto formal como semánticamente?

¿A qué se deben estas lagunas accidentales en el tratamiento de los posibles derivados dentro la serie de derivación ejemplificada en (3.1)? ¿A que no están documentadas, pues de hecho no se dicen, o a que el lexicógrafo "no ha pasado por alli" y, por tanto, no ha leído o escuchado determinada palabra de esta serie? Más bien creo que se debe a lo segundo: el lexicógrafo no ha pasado por allí o no ha caído en sus manos tal texto oral o escrito. Voy a poner un ejemplo significativo a este respecto: una charla no escuchada, en una determinada situación comunicativa, entre el presidente del gobierno y el ministro de economía de turno

Presidente.- La peseta se está desestabilizando...

Ministro.- Como ya le he indicado en varias ocasiones, dadas las circunstancias por las que atraviesa la macroestructura económica, la peseta es fácilmente desestabilizable. Pero esta desestabilización no implica mayores riesgos si se corrigen -y lo estamos intentando- ciertos factores desestabilizadores como pueden ser...

¿Qué pretendo mostrar y demostrar con esto? Dos ideas: primera, lo arbitrario que puede resultar (aplicado a esta serie de derivación con la que ejemplificamos) el criterio de registro o documentación para considerar tales palabras como reales, esto es, para integrarlas en el diccionario. Segunda y principal, cuestionar el carácter opcional que suele atribuirse a las RFP en la teoría actual, al menos en ciertas series parciales de derivación como la que estamos viendo. Dada la existencia de uno de los verbos en -iz-a- de (3.1), su nominalización mediante -ción y adjetivación mediante -dor o -ble es automática, predecible por tanto, y obligatoria como lo son los moldes o estructuras sintácticas de las frases en las que figuran como constituyentes nucleares. Dada la oración desestabilizar la peseta, automáticamente, de acuerdo con esta serie de derivación, yo puedo modular -y lo hago en este momento- el mismo significado léxico bajo los moldes o estructuras de las frase nominal y de la frase adjetiva correspondientes:

La desestabilización de la peseta.

(La peseta) es fácilmente desestabilizable.

(Un factor) desestabilizador de la peseta.

Algo similar, si no igual, ocurre con la serie de derivación ejemplificada en

7 El significado de los nombres en -ción "acción y efecto de V", concretamente el significado "efecto", viene dado por el significado causativo del verbo base que, como tal causativo, supone un esquema semántico oracional donde hay un causante (sujeto) que provoca el efecto o resultado en el causando o experimentador (CD): estabilizar la peseta = "hacer (más) estable la peseta". 
(3.2)

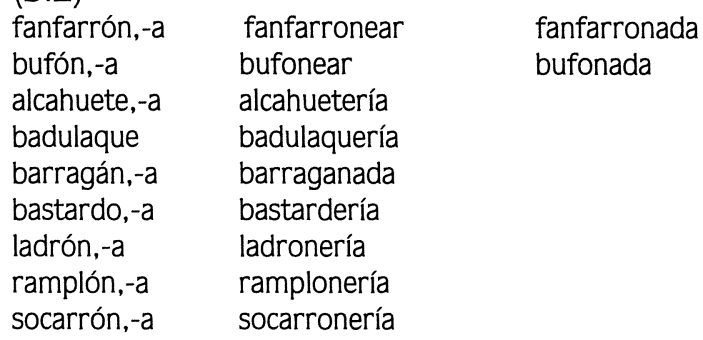

Se trata de una serie ternaria donde, como bases de derivación, figuran nombres con el rasgo de subcategorización [+ humano] ${ }^{8}$ que designan personas caracterizadas por su manera típica o habitual de actuar, casi siempre valorada negativa o peyorativamente. El verbo en -e-a-correspondiente verbaliza esa manera típica de actuar del nombre base (cf. fanfarrón, -a "que fanfarronea" / fanfarronear "hablar con arrogancia echando fanfarronadas"). Sobre la misma base de la que deriva el verbo en -e-a-, el español dispone de un sustantivo derivado (normalmente en -ada o -ería) para indicar "el acto propio o habitual realizado por el nombre base" (cf. fanfarronada "dicho o hecho propio de fanfarrón”). Esta serie ternaria está tan paralelada o correlacionada, que las paráfrasis o definiciones se hacen circulares. Pues bien, en (3.2) solo he puesto el verbo en -e-a-correspondiente en los dos primeros casos para que el lector, de acuerdo con su conocimiento práctico de la lengua, adivine cuáles figuran en el diccionario y cuáles no.

Sorprende que los diccionarios plasmen lagunas en esta serie, precisamente respecto al verbo en -e-a-, mientras registran con extrema exhaustividad el sustantivo derivado dando sistemáticamente los dobletes en -ada y -ería (y a veces en -ez, -ismo, etc.). Todo parece indicar, sin embargo, que la presencia de uno de los miembros derivados (sustantivo o verbo) de esta serie conlleva de manera prácticamente automática la copresencia del otro miembro. Se trata de una serie ternaria totalmente productiva, abierta o disponible para formarse sobre cualquier base que indique peyorativamente una manera típica o habitual de proceder ${ }^{9}$.

Sigamos con la comparación y el contraste entre diccionario y formación de palabras para mostrar cómo difieren parcialmente en cuanto a objeto y a objetivos, pero también cómo pueden complementarse pues, en definitiva, ambos dominios se ocupan del léxico de una lengua.

Sabido es que el componente léxico de una lengua es el más propenso a la variación o cambio y, por tanto, el componente donde más abundan las irregularidades. Las RFP permiten crear nuevas palabras que, en principio, son regulares tanto formal como semánticamente. Pero, una vez formada la palabra objeto de la RFP en cuestión, esta se incorpora al caudal léxico de una lengua y, con el paso del tiempo, puede ad-

8 Inicialmente concebidos como adjetivos, pero que automáticamente son recategorizables como sustantivos en su mayoría (vid. I. BoSQUE (1989), cap. 5).

9 Vid. J. Pena (1993), pp. 237-243. 
quirir formas y /o significados irregulares, impredecibles por tanto. Conviene tener en cuenta, a este respecto, que una lengua natural es un sistema en parte formal y funcional y en parte también un sistema resultado de estados anteriores de lengua.

Si las RFP se encargan de describir las regularidades del léxico, ¿dónde se colocan las irregularidades? ¿En el diccionario? Hay que hacer constar, en este sentido, que en el léxico de una lengua las palabras a menudo muestran regularidades al lado de propiedades peculiares. Es en este ámbito donde semántica, sintaxis y formación de palabras pueden complementar su labor para describir más adecuadamente los hechos. Veamos unos cuantos casos: los ejemplificados entre (4) y (8).

Se suele afirmar que, para poder hablar de una relación derivativa entre la palabra base de derivación y la palabra derivada, debe haber una relación formal y semántica. Según esto, las relaciones derivativas serían siempre a la vez formales y semánticas. Pues bien, en

(a)

opaco-opacidad

bueno-bondad (b)

cuerpo-corporal

leche-lácteo (c)

juego-lúdico

hermano-fraternal

se muestran parejas de palabras relacionadas semánticamente, pero separadas en tres grupos según el grado de irregularidad que presentan en el aspecto formal: (a) alomorfía condicionada fonológicamente, (b) alternancia "forma popular/formal culta", (c) supletivismo léxico (raíces distintas para la palabra base y para la palabra derivada). De la alomorfía ejemplificada en (4a) puede dar cuenta el estudio de la formación de palabras; también de la alternancia en (4b) entre forma popular y forma culta porque, como veremos, el español, al igual que las demás lenguas románicas, dispone de dos subsistemas de reglas de formación de palabras. De las parejas de formaciones supletivas tiene que encargarse el lexicógrafo.

Si en (4) figuran parejas de palabras regulares en cuanto a la relación semántica, pero con distintos grados de irregularidad en cuanto a la correlación formal, en (5)(8) se muestra el caso inverso: parejas de palabras relacionadas formalmente pero con distintos grados y/o tipos de irregularidad en cuanto a la correlación semántica ${ }^{10}$ :

(5)

$\begin{array}{ll}\text { puro,-a } & \text { purificar } \\ \text { sólido,-a } & \text { solidificar } \\ \text { justo,-a } & \text { justificar } \\ \text { vero,-a } & \text { verificar } \\ \text { clasificar } & \text { clasificable } \\ \text { justificar } & \text { justificable } \\ \text { agradar } & \text { agradable }\end{array}$

"hacer algo (más) A"
"hacer algo (más) A"
*"hacer algo (más) A"
*"hacer algo (más) A"
"que puede ser Vado"
"que puede ser Vado"
*"que puede ser Vado"

10 Los ejemplos de (5), (7) y (8) están tomados de Corbin (1976a), Bosque (1982) y LáZARO CARRETER (1971), respectivamente. 
(6)

Admitieron la solicitud.

Admitieron que presentara la solicitud.

Readmitieron la solicitud.

*Readmitieron que presentara la solicitud.

Juan dijo que llegaría Pedro.

*Juan dijo la llegada de Pedro.

Juan predijo que llegaría Pedro.

Juan predijo la llegada de Pedro.

(7)

$\begin{array}{lll}\text { aclarar } & \text { aclarado } & \text { aclaración } \\ \text { desembocar } & \text { desembocadura } & - \\ \text { romper } & \text { rotura } & \text { ruptura } \\ \text { padre } & \text { paterno } & \text { paternal } \\ \text { claro } & \text { claridad } & \text { claridad } \\ \text { dulce } & \text { dulzor } & \text { dulzura } \\ \text { grande } & \text { agrandar engrandecer } \\ \text { El aclarado de la ropa / la aclaración de una idea. } \\ \text { La desembocadura del río / *La desembocadura de las negociaciones. } \\ \text { La rotura de la tubería / La ruptura de las negociaciones. } \\ \text { Potestad paterna (*paternal ) / Carácter paternal (*paterno). } \\ \text { La claridad del día / de sus ideas. } \\ \text { El dulzor de la miel / La dulzura de su carácter. } \\ \text { Agrandar algo / Engrandecer a alguien. }\end{array}$

(8)

Bautizar ${ }^{1}$. Administrar el sacramento del bautismo e imponer nombre a un ser humano.

Bautizar $^{2}$. Imponer nombre a un animal o cosa.

Bautizar $^{3}$. (humor). Imponer apodo a una persona, animal o cosa.

Bautizar $^{4}$. (humor). Verter líquido sobre alguien 0 algo.

Bautizar 5 . (humor). Adulterar algo echándole agua.

Bautizar a un niño/El bautizo de un niño.

Bautizar un barco/*El bautizo de un barco.

Bautizar a un amigo/*El bautizo de un amigo.

Bautizar a un paseante/*El bautizo de un paseante.

Bautizar el vino/*El bautizo del vino.

En (5) figuran palabras derivadas con la misma estructura mórfica pero, mientras en unas el significado es composicional y predecible a partir del significado de sus constituyentes y de la RFP correspondiente, en otras no. Así purificar y solidificar significan o son parafraseables por "hacer algo (más) puro, sólido", pero justificar y verificar no significan "hacer algo (más) justo, verdadero". Del mismo modo, mientras que clasificable y justificable admiten la paráfrasis "que puede ser clasificado, justificado", agradable no.

En (6) la irregularidad de la relación no afecta al significado léxico en sí, sino a los rasgos de subcategorización. De la palabra base a la palabra derivada puede haber 
transmisión, elisión o adición de rasgos de subcategorización. En el primer caso no hay irregularidad, sí en los casos de elisión (admitir/readmitir) y adición (decir/predecir). De este tipo de irregularidades puede y deben dar cuenta tanto el estudioso de la sintaxis como el de la formación de palabras y, de este modo, ayudar al lexicógrafo.

En (7) la irregularidad de la relación semántica tampoco afecta estrictamente al significado léxico, sino a los rasgos de selección correspondientes a la palabra base y a la palabra derivada, aunque en el diccionario figuren como acepciones diferentes: la que se entiende como el sentido recto, primitivo u originario y la que se interpreta como el sentido derivado o figurado. Pues bien, en (7) se puede comprobar que en muchos casos la palabra derivada es distinta en correspondencia con la distinción "sentido recto/sentido figurado" presente en la palabra base de derivación. Lo que sucede realmente es que hay distintos rasgos de selección por parte de las dos palabras derivadas. También este es un terreno donde confluyen los intereses del lexicógrafo y de los estudiosos de la sintaxis y de la formación de palabras.

En (8) nos encontramos con otro tipo de anomalía o irregularidad, que afecta a la correspondencia entre las acepciones de la palabra base y las de la palabra derivada. En efecto, se puede comprobar lo poco frecuente que resulta el caso en que la palabra derivada se corresponde con la palabra base en todas las acepciones de esta. Como muestra Lázaro Carreter ${ }^{11}$, de las cinco acepciones que figuran para bautizar en el DRAE (1970), el sustantivo derivado bautizo selecciona solo la primera. En el saber léxico convencional se acepta el bautizo de un niño, pero no *el bautizo de un barco, *el bautizo de un amigo, etc. Y, sin embargo, el DRAE define bautizo como "acción de bautizar"12.

Paso a destacar algunos hechos donde el estudio de las RFP puede servir de ayuda a la lexicografía, especialmente en lo que concierne a la parte definitoria del artículo o entrada del diccionario.

Los ejemplos de (9.1) y (9.2) forman parte del subsistema de la derivación verbal y muestran diferencias de tipo aspectual que se repiten con cierto grado de sistematicidad. Ya hemos visto, a propósito de la serie ternaria de derivación ejemplificada en (3.2), que el verbo derivado en -e-a- puede expresar la modalidad de aspecto "habitualidad" especialmente sobre una determinada clase de bases que, precisamente, designan personas que se caracterizan por su manera habitual de proceder. Se trata del hecho conocido como "filtrado de rasgos" de la palabra base a la palabra derivada, pues la nota aspectual de habitualidad ya está presente en la palabra base. Pues bien, en

11 Vid. F. LÁzaro CARRETer (1971), p. 373.

12 Por lo que respecta al segundo sustantivo (bautismo), los diccionarios, aparte de dar su acepción exclusiva como "sacramento", lo hacen sinónimo de bautizo; pero no lo es. Dice Lázaro Carreter: "y tampoco (bautismo) es sinónimo del bautizo resultante de la transformación de bautizar ${ }^{1}$, al menos en un caso: podemos hablar del bautismo de Jesucristo, pero no -me parece- del *bautizo de Jesucristo" (F. LÁZARO CARRETER (1971), p. 373). 
$(9.1)$

(a)

$\begin{array}{ll}\text { coz } & \text { cocear } \\ \text { vuelta } & \text { voltear } \\ \text { golpe } & \text { golpear }\end{array}$

(b)

porra aporrear

hacha hachear

martillo (c)

$\begin{array}{ll}\text { piedra } & \text { apedrear } \\ \text { punto } & \text { puntear } \\ \text { silabear } & \\ \text { gota } & \text { gotear }\end{array}$

tenemos otra serie de verbos derivados en -e-a- que coinciden en expresar la modalidad aspectual "iteratividad". La derivación mediante -e-a- en la formación de verbos iterativos es muy productiva, ilimitada. Como se sabe, un proceso es iterativo cuando su realización supone la ejecución de una serie sucesiva de actos. Es un proceso de duración interna ilimitada, pero integrado por una pluralidad, intermitencia o sucesión de actos télicos momentáneos. Esta modalidad aspectual se comprueba muy bien en verbos derivados de sustantivos que indican precisamente un acto (cf.(a) $\mathrm{COZ} \longrightarrow$ cocear "dar coces una caballería", vuelta $\rightarrow$ voltear "dar vueltas a una persona o cosa", gol$p e \rightarrow$ golpear "dar repetidos golpes a alguien o algo"), o cuando el sustantivo base se incorpora al verbo derivado como instrumento mediante el cual se ejecuta una serie sucesiva de actos (cf. (b) porra $\rightarrow$ aporrear "golpear con una porra", hacha $\rightarrow$ hachear "dar golpes con el hacha de cortar", martillo $\rightarrow$ martillear "golpear con un martillo"), como primer objeto o término actuado en una estructura triactancial (cf. en (c) piedra $\rightarrow$ apedrear "tirar o arrojar piedras a una persona o cosa", punto $\rightarrow$ punte$a r$ "señalar con puntos u otras señales un escrito u otro objeto"), como objeto de una estructura biactancial (cf. en (c) sílaba $\rightarrow$ silabear "pronunciar algo marcando la separación entre las sílabas") o como término experimentador en una estructura monoactancial (cf. en (c) gota $\longrightarrow$ gotear "caer un líquido gota a gota") ${ }^{13}$.

En (9.2) se muestra un pequeño ámbito, el de los nombres de color, donde el verbo derivado en -e-a-, que siempre comparte la base con otros verbos derivados, tiende a plasmar también diferencias de tipo aspectual ${ }^{14}$. Son pocos los verbos, pero significativos. Veamos cómo se definen en los diccionarios algunos de estos verbos formados sobre la misma base, un nombre de color:

(9.2)

colorear 1. tr. Dar color, teñir de color. 3. intr. Mostrar una cosa el color colorado que en sí tiene. 4. Tirar a colorado, u.t.c. prnl. 5. Tomar algunos frutos, como la cereza, la guinda, el tomate, el pimiento, etc., el color encarnado de su madurez. colorar = colorear $1,4,5$. purpurear 1. Mostrar una cosa el color de púrpura que en sí tiene. 2. Tirar a purpúreo. purpurar. Teñir de púrpura.

azulear 1. Mostrar alguna cosa el color azul que en sí tiene. 2. Tirar a azul, tener algo de azul. azular. Dar color azul a algo.

negrear 1 . Mostrar una cosa la negrura que en sí tiene. 2 . intr. Tener o tomar color negruzco. 
ennegrecer. Poner(se) negro.

rojear 1. Mostrar una cosa el color rojo que en sí tiene. 2. Tender una cosa al color rojo (rojizo. Que tiende a rojo).

enrojar. Poner roja una cosa.

enrojecer(se). Poner(se) roja una cosa.

Como es normal, a veces los distintos verbos se superponen para expresar el mismo rasgo. Aquí se puede ver que hay intersección entre los verbos en -e-a-, $-a-y-e c-$ $e$ - para indicar causatividad y/o incoatividad. Pero hay dos rasgos aspectuales que tiene el verbo en -e-a-, que no comparte con los demás verbos derivados. Son los definidos como "tener o mostrar el color X" y "tirar al color X". La primera definición es fácilmente identificable: indica un estado. La segunda, un poco más difícil de captar, se puede delimitar e identificar si se contrasta con la noción de "estado" y se compara con lo que ocurre en los adjetivos derivados dentro de la derivación homogénea:

BASE
'color X'
amarillo,-a
azul
bermejo
blanco
negro
rojo
verde

ADJETIVO DERIVADO
'que tira al color X'
amarillento
azulino, azulado, azuloso
bermejizo
blancuzco, blanquecino
negruzco
rojizo
verdoso, verderón

SUSTANTIVO
amarillez
bermejura
blancura
negrura
rojez
verdor

Concebida la noción de "color" como propiedad accidental o estado transitorio susceptible de ser alcanzado, se ve que "tirar a" equivale a "estar a punto de ser o estar" pero aún no a "estar". Si se recurre a la gradación del adjetivo con cuantificadores y se establecen los dos límites extremos de la gradación (infralativo: muy poco amarillo y superlativo: muy amarillo), se ve que amarillento, azulado, negruzo, rojizo, etc. están a punto de alcanzar el grado positivo, pero aún no lo alcanzan. En este sentido, son parafraseables por el adjetivo base combinado con el cuantificador casi: rojizo = "casi rojo". Pues bien, la misma relación que hay entre los significados de rojo y rojizo la hay en rojear entre los significados "mostrar una cosa el color rojo que en sí tiene" y "tender una cosa al color rojo". La diferencia es de tipo aspectual y, como muy bien indica Cartagena ${ }^{15}$, "se refiere a la posibilidad que tiene el hablante de referirse a determinadas fases (comienzo, medio o fin) del transcurso de la acción verbal o a un punto inmediatamente anterior a su comienzo o fin". Las fases que intervienen en estas series de formaciones que ahora nos ocupan son la "inminente" y la "ingresiva" (también denominada "incoativa"): la fase inminente (expresada por la perífrasis estar a punto de + infinitivo) "permite contemplar la acción verbal desde un punto de vista inmediatamente anterior a su comienzo"16; la fase ingresiva (parafraseable por ponerse + par-

16 Cf. N. Cartagena (1978), p. 396. 
ticipio) "contempla el comienzo de la acción"17. Aplicada la distinción a las series ejemplificadas en (9.2), se puede comprobar lo siguiente: dada una situación estativa concebible como transitoria (nombre base y verbo en -e-a-), se recategoriza como dinámica para indicar las fases inminente (verbo en -e-a-) e ingresiva (verbo en -a- y/o $e c-e-)$. Como se puede observar en las definiciones del diccionario, la situación estativa y la fase inminente son privativas del verbo en -e-a-.

Los ejemplos de (10) permiten mostrar que el orden de aplicación de las RFP es pertinente:

(10.1) inmortalizar $\rightarrow \quad$ inmortalizable ${ }^{1}$ mortalizable $\rightarrow \quad$ inmortalizable ${ }^{2}$

(10.2)

(a) eructar
insultar
raptar

eructo
insulto
rapto

(b)

clausurar
ingresar
trasladar

(c)

$\begin{array}{ll}\text { cambiar } & \text { cambio } \\ \text { derribar } & \text { derribo } \\ \text { atracar } & \text { atraco }\end{array}$

En (10.1) el significado de inmortalizable es ambiguo y la ambigüedad se resuelve teniendo en cuenta el orden de aplicación de las RFP: si la base es inmortalizar y se obtiene mediante la sufijación de -ble, inmortalizable ${ }^{1}$ significa "que puede ser convertido en inmortal"; si la base es mortalizable y se obtiene mediante la prefijación de in, inmortalizable ${ }^{2}$ significa "que no puede ser convertido en mortal".

En (10.2) también se plantea el orden de derivación, en este caso, entre el verbo y el sustantivo correspondiente. Nos encontramos con parejas de formaciones cuyos significantes son cuantitativamente iguales (la $-r$ del verbo no forma parte del tema, sino que es formante flexivo) y a veces también cualitativamente iguales (cf. clausurar/clausura). Cuando se contrastan dos formaciones diferentes en cuanto a la extensión del significante, se admite como natural que el sentido de la derivación vaya del significante más corto al más largo; pero, cuando se trata de formaciones cuyos significantes son segmentos cuantitativamente iguales, la ausencia de diferencia cuántica en el significante conlleva falta de pauta formal para decidir el sentido de la derivación. Ante la ausencia de criterios formales, se recurre a criterios de tipo semántico. Dicho criterio ha sido objeto de formulaciones más o menos similares ${ }^{18}$. Una de ellas puede ser la propuesta por Corbin ${ }^{19}$ : "Un sustantivo parafraseable por la "acción o el acto de V" y desprovisto de sufijo deriva del verbo correspondiente. Un sustantivo no parafraseable por "la acción o el acto de V" no es derivado del verbo, sino base de derivación del verbo". Según esta formulación, los sustantivos ejemplificados en (10.2) derivan del verbo correspondiente, pues son parafraseables por la "acción de V" o "el acto de V".

19 Cf. D. CoRBin (1976a), p. 59. 
En los estudios tradicionales sobre la formación de palabras se han utilizado como pautas datos de tipo etimológico e histórico, que no siempre resultan válidas en el estudio sincrónico del léxico. Sincrónicamente, los sustantivos de (10.2) funcionan como sustantivos postverbales. Sin embargo, diacrónicamente responden a esquemas de derivación distintos:

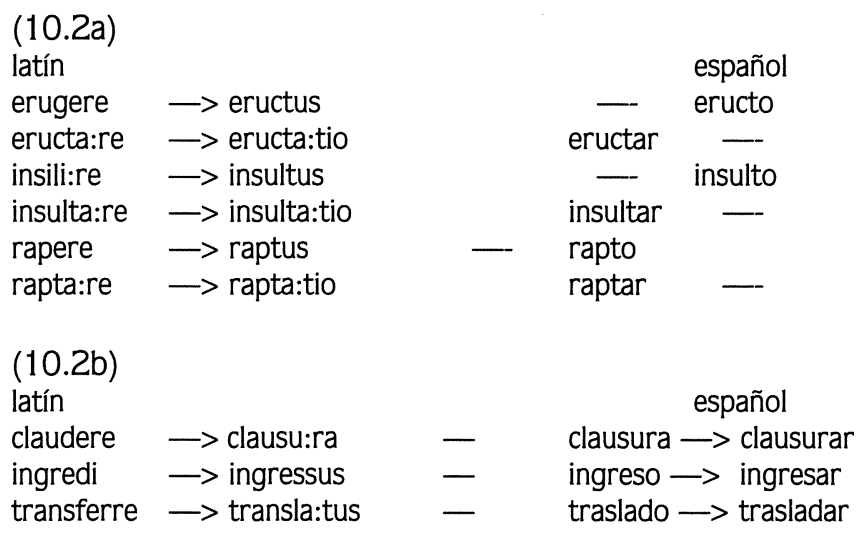

$$
\begin{aligned}
& (10.2 c) \\
& \text { español } \\
& \text { cambiar } \rightarrow \text { cambio } \\
& \text { derribar } \rightarrow \text { derribo } \\
& \text { atracar } \quad \rightarrow \text { atraco }
\end{aligned}
$$

En (10.2a) la relación verbo-sustantivo es el resultado de la traslación del sustantivo de un esquema de derivación a otro; en (10.2b) el sustantivo es la base de derivación del verbo, que es de creación romance; en (10.2c), por el contrario, es el verbo la base de derivación del sustantivo ${ }^{20}$.

Para terminar con esta exposición, quiero retomar los ejemplos de (4b) ejemplificados ahora en (11), es decir, aquellas series de derivación en las que hay alternancia entre formaciones populares y formaciones cultas, para referirme a la distinción palabra popular/palabra culta desde el punto de vista de las RFP:

$\begin{array}{llll}\text { (11) } & & & \\ \text { cuerpo } & \text { corporal } & \text { padre } & \text { paterno } \\ \text { leche } & \text { lácteo } & \text { pecho } & \text { pectoral } \\ \text { ojo } & \text { ocular } & \text { ombligo } & \text { umbilical }\end{array}$

Dentro de una misma familia léxica, hay series homogéneas de formaciones populares (volver, envolver, desenvolver, desenvolvimiento, etc.) o de formaciones cultas 
(acto, actual, actualizar, actualización, etc.); pero predominan las series heterogéneas (leche, lechal, lechoso, lechero, lechería/lácteo, láctico, lactar, lactante, lactación; año, añal, añejo, añoso/anual, bienal, trienal, perenne, bienio, trienio, decenio, milenio, etc.). En estas series heterogéneas no es posible predecir cuál de los dos temas, el culto o el popular, servirá de base de derivación. Por otro lado, una vez que se opta por una de las bases de derivación, no siempre se puede prever el afijo o los afijos correspondientes dentro de cada subsistema de derivación pues, aparte de los hechos de sinonimia afijal, no siempre hay una relación biunívoca entre un determinado afijo y la forma culta o popular de la base. Es verdad que hay algunos sufijos cultos que seleccionan bases cultas: no son posibles, por ejemplo, formaciones como *áñeo o *lécheo porque el sufijo -e-o está restringido a formaciones científicas o técnicas sobre bases cultas; pero la mayoría de los afijos no distinguen entre bases cultas y populares: al lado de añal está anual; al lado de leñoso o añoso, con -os-o sobre bases populares, están luctuoso o defectuoso, aguoso y acuoso, etc. Aun en los casos en que el afijo aparece desdoblado en las variantes culta y popular, no hay una correlación formal sistemática entre base y afijo: están hinchar e hinchazón frente a inflar e inflación, pero también degollación, humillación, etc.; están avaricia y pigricia, frente a pereza, pero también delicadeza, malicia y maleza, justicia y justeza; -icie aparece sobre bases cultas en calvicie o planicie y -ez sobre bases populares en chochez, vejez o delgadez, pero también sobre bases cultas en ordinariez, ridiculez, insulsez o flac(c)idez.

¿Cómo tratar estas series heterogéneas de derivación de manera adecuada y operativa desde un punto de vista sincrónico? Descartarlas del ámbito de estudio de la morfología descriptiva del español actual supone dejar fuera más del ochenta por ciento del léxico. De algún modo hay que incorporarlas como objeto de estudio. Ahora bien, metodológicamente no sirve de nada comparar palabras estructuralmente diferentes. Con decir que a menudo una formación derivada culta (=latina o latinizada) corresponde a una palabra base de derivación bajo forma popular, no se resuelve nada.

Una consideración previa. Se define una lengua como un sistema estructurado de signos. Pero las lenguas naturales, como lenguas históricas, son también el resultado de etapas anteriores, incluido el propio latín en el caso del español y de las demás lenguas románicas. Esta consideración tiene un corolario metodológico de enorme importancia para las reglas de formación de palabras en español: el español hereda del latín no solo palabras (a modo de continuación en las formaciones populares y a modo de incorporación intermitente en las formaciones cultas), sino también pautas o reglas en la formación de palabras cultas. Por poner un ejemplo, los sufijos -tiv-o/a y -tori-o/a, formadores de adjetivos postverbales, son productivos tanto en latín como en español. Si observamos las formaciones con estos sufijos existentes hoy en español, hay unas que tienen precedente latino y otras no. Según el DCELC (de J. Corominas y J. A. Pascual), son creaciones hispánicas: aclaratorio, declaratorio declarativo, atentatorio, eliminatorio, estimativo estimatorio, perceptivo, supletivo supletorio, provisorio, disuasivo disuasorio, persuasivo persuasorio, etc. (sobre los verbos aclarar, declarar, atentar, eliminar, estimar, percibir, suplir, proveer, disuadir y persuadir). Frente a -der-o/a (cf. asar asadero,-a, hacer hacedero,-a, venir venidero,-a), sufijo que responde a una pauta romance de formación de palabras, -tori-o/a responde a una pauta 
de formación latina que se incorpora al español como pauta de formación de palabras cultas igualmente productiva ${ }^{21}$.

Teórica y metodológicamente, pues, hay que tener en cuenta el carácter heterogéneo del léxico y distinguir dos pautas o tipos de reglas en la formación de palabras: la formación de palabras sobre base popular y la formación de palabras sobre base culta (=latina o griega). Las dos pautas de formación deben estudiarse separadamente, al margen de que las formaciones existentes en una determinada serie léxica sean el resultado de estas dos pautas de formación diferentes (vid. MaRCHAnd, 1951). Las formaciones populares se crean (o son analizables) de acuerdo con las RFP del español; las formaciones cultas se crean (o son analizables) de acuerdo con las RFP del latín incorporadas al español. Solo así se pueden explicar alternancias como las ejemplificadas. Que entre cuerpo y corporal o leche y lácteo hay la misma relación semántica resulta evidente para cualquier hablante del español; pero no hay una relación en cuanto a las pautas de formación: las palabras corporal y lácteo están formadas de acuerdo con pautas de formación latinas.

Una consecuencia metodológica pertinente para poder operar con estas series heterogéneas de derivación es reproducir la base de derivación inicial en su forma culta (=latina o griega) e introducirla en el léxico, al lado de la variante radical popular, como raíz o tema de palabra inexistente, esto es, raíz o tema que no existe como palabra simple. Así:

cuerp- ( corp-): cuerpo, corpazo, corpezuelo, corpachón...

corpor-: corporación, corporal(-idad), corporativo,-a (-ismo, -ista), (in)corpóreo,-a, corporeidad, corporificar, incorporar...

lech-: leche, lechal, lechero,-a (-ía), lechoso,-a...

lact-: lactar (-ción, -nte), lácteo,-a, láctico,-a...

Creo que la inclusión de la variante radical culta como tema de palabra inexistente, al lado de la variante radical popular, es inevitable en cuanto que sirve de base de derivación de formaciones cultas ya existentes y de otras posibles pero aún no existentes. Además, la inclusión de ambas variantes en el diccionario debería ordenarse de forma adecuada para que el usuario dispusiese de esta información básica en una misma entrada.

21 No tiene sentido, pues, desde un punto de vista sincrónico (ni diacrónico, cuando se trata de formaciones regulares formal y semánticamente) averiguar si tales formaciones tienen o no precedente latino. Y tiene mucho menos sentido inventar bases etimológicas raras de modo arbitrario, como se hace en el DRAE en sucesivas ediciones. A modo de muestra: atentatorio,-a proviene del participio attempta:tus,-a,-um; perceptivo,-a de percipere; provisorio,-a de la forma de supino provi:sum, al igual que disuasivo,-a del supino dissua:sum; pero disuasorio,-a de dissua:sor, etc. Esta manera asistemática de trabajar no lleva a ninguna parte. Cabría objetar que tales formaciones tienen siempre precedente latino, pero que en algunos casos el etimólogo aún no lo ha encontrado y que, mientras tanto, a esperar y a "colocarles étimos" a estas pobres formaciones hispánicas huérfanas. La competencia del hablante es más fiable: cualquier hablante español sabe que el sistema de derivación de su propia lengua le permite derivar adjetivos en -torio y, especialmente, en -tivo sobre cualquier base verbal culta de tema en -a- y en - $i$ - de esquema transitivo o causativo. 
Con esto doy por terminada la exposición. Lo que he pretendido con las observaciones hechas ha sido mostrar el modo como gramática, formación de palabras, lexicografía y lexicología están interrelacionadas y, más concretamente, la manera en que el estudio de la formación de palabras se conforma como una disciplina puente o de transición entre los otros dos dominios: el de la gramática y el del léxico.

\section{BiBLIOGRAFÍA}

Bosque, IGnaCIO (1982): “Más allá de la lexicalización”, BRAE, 62, pp. 103-158.

BosQUe, IGNaCio (1989): Las categorías gramaticales, Madrid, Síntesis.

Bosque, Ignacio y Manuel Pérez Fernández, (1987): Diccionario inverso de la lengua española, Madrid, Gredos.

CARTAGENA, Nelson (1978): "Acerca de las categorías de tiempo y aspecto en el sistema verbal del español”, RSEL, 8/2, pp. 373-408.

CoRBin, Danielle (1976a): "Peut-on faire l'hypothese d'une derivation en morphologie?", en Jean Claude Chevalier, ed., Grammaire transformationnelle: syntaxe et lexique, PUL, pp. 49-91.

Corbin, Danielle (1976b): “Le statut des exceptions dans le lexique”, Langue Française, 30, pp. 90-110.

CoRBIN, DANIElle (1980): “Compétence lexicale et compétence syntaxique”, Modèles linguistiques, $11 / 2$, pp. 52-138.

Coseriu, EugenIo (1967): “Sistema, norma y habla”, en Teoría del lenguaje y lingüística general, Madrid, Gredos, pp. 11-113.

Coseriu, Eugenio (1978): "Semántica y gramática”, en Gramática, semántica y universales, Madrid, Gredos, pp. 128-147.

LÁzaro CarReter, Fernando (1971): “Transformaciones nominales y diccionario”, RSEL, 1/2, pp. 371-379.

MARCHAND, Hans (1951): “Esquisse d'une description des principales alternances dérivatives dans le français d'aujourd'hui", Studia Linguistica, 5/2, pp. 95-112.

PenA, Jesús (1976): Usos anómalos de los sustantivos verbales en el español actual, Verba, Anejo 6.

PenA, Jesús (1991): “La palabra: estructura y procesos morfológicos”, Verba, 18, pp. 69-128.

PENA, Jesús (1993): “La formación de verbos en español: la sufijación verbal”, en Soledad Varela, ed., La formación de palabras, Madrid, Taurus Universitaria, pp. 217-281 y 389-400. 